\title{
A case study of outlier event on solar irradiance forecasts from the two NWPs with different horizontal resolutions
}

\author{
Hideaki Ohtake ${ }^{1,2,}{ }^{*}$, Takumi Takashima ${ }^{1}$, Takashi Oozeki ${ }^{1}$, Joao Gari da Silva Fonseca Jr. ${ }^{1}$, and \\ Yoshinori Yamada ${ }^{2}$ \\ ${ }^{1}$ National Institute of Advanced Industrial Science and Technology (AIST), OSL, Central 2, 1-1-1, Umezono, Tsukuba, \\ Ibaraki 305-8568, Japan \\ ${ }^{2}$ Meteorological Research Institute (MRI), Japan Meteorological Agency (JMA), 1-1 Nagamine, Tsukuba, Ibaraki 305-0052, \\ Japan
}

\begin{abstract}
Photovoltaic (PV) power generation is directly effected by global horizontal irradiance (GHI) and has also large variations in spatial and/or temporal scales. For a safety control of an energy management system (EMS), a day-ahead forecast or several hour forecast of solar irradiance by a numerical weather prediction model (NWP) becomes important for a control of reserve capacity (thermal power generation, etc.). In particular, a large forecast error of PV power and/or GHI forecasts has to be prevented in the EMS. The Japan Meteorological Agency (JMA) developed two NWPs with different horizontal resolutions. First one is a mesoscale model with horizontal grid spacing of $5 \mathrm{~km}$ and second one is a local forecast model with that of $2 \mathrm{~km}$. The two NWPs have been used as an operational model in JMA. In this study, GHI forecasts obtained from the two models are validated and conducted a case study for large forecast error (outlier events) case of GHI.
\end{abstract}

\section{Introduction}

Recently, many photovoltaic (PV) systems have been installed in Japan islands since an introduction of feed-intariff in 2012. PV power generation has large variability in spatial and temporal scales due to variations of global horizontal irradiance (GHI). For a safety control of electric energy management system (EMS), PV power generation and/or GHI forecasts has been expected. For a method of GHI day-ahead forecasts, it is known that a numerical weather prediction model (NWP) is a useful tool. However, forecast results from NWPs include sometimes large forecast errors (or outlier events). For the safety EMS, outlier events of GHI day-ahead forecasts should be avoided.

The Japan Meteorological Agency (JMA) developed some kind of NWPs and operationally has used their NWPs to prevent natural disasters. Authors performed a validation of GHI day-ahead forecasts from the JMA NWPs and investigated forecast error characteristics $[1,2]$ in cooperation with the JMA. An estimation of confidence intervals of hourly GHI forecasts has been investigated [3]. However, outlier event of GHI forecasts has not been investigated enough. A case study of GHI large forecasts errors obtained from two NWPs with different horizontal grid spacing is performed in this study.

\footnotetext{
* e-mail: hideaki-ootake@aist.go.jp
}

\section{Data}

\subsection{Observation}

In order to validate GHI forecasts from the NWPs, surfaceobserved GHI data at operational observatory stations of the JMA were used. Target area is the Kanto area (the eastern part of the Japan islands or around Tokyo, Fig. 1). Tokyo electric power company (TEPCO) has controlled their electric power system within this area. JMA six stations observed GHI values (Tokyo, Tsukuba, Choshi, Utsunomiya, Maebashi and Kofu) are located (squares in Fig. 1b) within the TEPCO area. To validate GHI forecasts, satellite-estimated GHI datasets (e.g., JST CREST TEEDA) [4] also were used.

\subsection{Model}

A mesoscale model (MSM) with horizontal grid spacing of $5 \mathrm{~km}$ and a local forecast model (LFM) with horizontal grid spacing of $2 \mathrm{~km}$ from the JMA were analyzed in this study. MSM and LFM [5], which based on a physical model (or NWP) [6], have been used as operational models in the Japan islands (Fig. 1a) to prevent meteorological disasters (JMA web site) [5]. MSM performed $39 \mathrm{~h}$ forecast every $3 \mathrm{~h}$. LFM performed $9 \mathrm{~h}$ forecasts every hour. GHI forecasts from the two models are provided hourly. For validation of GHI forecasts for spatially wide area (or TEPCO, see Fig. 1b), hourly observations at the six stations are 


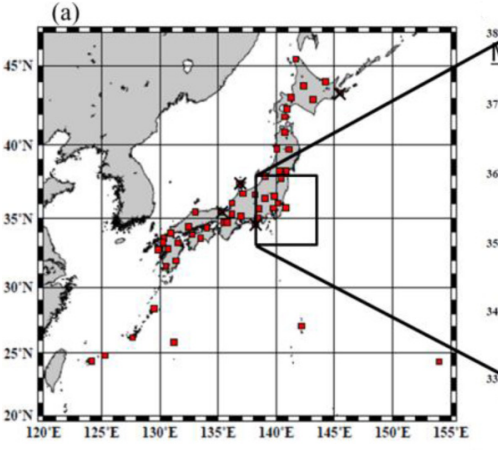

The location of $\mathrm{GHI}$ observation sites.

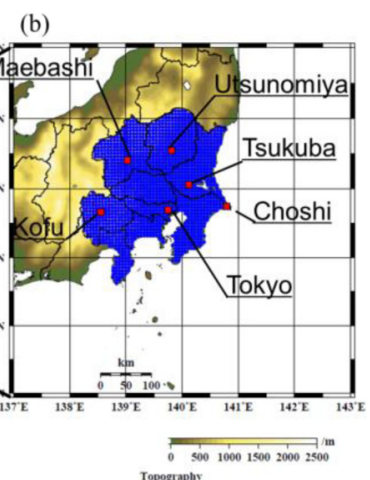

Topography
Fig. 1. (a) Map of Japan area and (b) close-up view of the Tokyo electric power area (TEPCO). Red squares and blue dots mean the JMA observations and the locations of MSM model grids within TEPCO area, respectively.

integrated every hour while GHI forecasts for each model grids (about 1500 grids) are also integrated within the TEPCO area (blue area in Fig. 1b).

\subsection{Definition of large forecast error}

In this study, we defined "a large error" of GHI forecasts and select outlier events. Here, a forecast error parameter which normalized by the extra-solar irradiance (EXT) is given in the following equation

$$
\left|\frac{\mathrm{FCST}-\mathrm{OBS}}{\mathrm{EXT}}\right|>0.3 \text {. }
$$

Here, FCST and OBS are GHI day-ahead forecasts and observations, respectively. The value of 0.3 is a threshold of large forecast errors decided in this study. Given this value, about $5 \%$ (about 10 cases) of large forecast error cases could be selected from all the events in one year. However, there is no physical meaning for the value of 0.3 in this study. We shows the total 13 cases of solar irradiance outlier events during 2014 (see Tab. 1) for the TEPCO area. There were six events for positive outlier events and seven events for negative outlier events in the one year. Generally, positive outlier events are found from winter to early summer season and negative outlier events are found from summer season to autumn. In Section 3, a case study of March 14, 2014 (No. 3 event in Tab. 1, positive outlier events), which has the longest time range of large forecast errors $(5 \mathrm{~h})$, will be analysed in this paper.

\section{Case study}

\subsection{Overview}

Figure 2a shows the surface weather chart around Japan islands at 09 JST on March 14, 2014. A low pressure $(980 \mathrm{hPa})$ with cold front is located around north eastern part of Japan islands over the Pacific Ocean and move toward east direction with decreasing the pressure on the central part of the low pressure. Figure $2 \mathrm{~b}$ shows the satellite visible image at 12 JST on the same day. Cloud fields with accompanying the cold front from the low pressure over the Pacific Ocean prevailed around TEPCO area.

\subsection{Time series of GHI}

Here, we investigated GHI time series for the regional area. Figure 3 means time series of hourly GHI values for the TEPCO region of both observations and the two model forecasts. Forecast results with different initialization times are shown by different colors. On MSM GHI forecasts from 00 UTC or 03 UTC initialization times on the previous day, significant overestimations are found on the day time (about $800 \mathrm{~W} / \mathrm{m}^{2}$ in MSM forecasts compared to about $400 \mathrm{~W} / \mathrm{m}^{2}$ in observations). On the other hand, MSM forecasts with 21 UTC initialization time (06 JST on a target day) tend to reduce forecast errors (yellow color). The difference from GHI observations reduced from $400 \mathrm{~W} / \mathrm{m}^{2}$ to $200 \mathrm{~W} / \mathrm{m}^{2}$. However, the overestimation of GHI forecast with 21 UTC initialization time is remained compared to GHI

Table 1. Selected outlier events of solar irradiance day ahead forecasts during 2014.

\begin{tabular}{|c|c|c|}
\hline & yyyy-mm-dd hour & normalized errors \\
\hline \multirow[t]{2}{*}{ No.1 } & 2014-01-08T11:00:00 & -0.33 \\
\hline & 2014-01-08T12:00:00 & -0.35 \\
\hline \multirow[t]{4}{*}{ No.2 } & 2014-02-04T10:00:00 & 0.33 \\
\hline & 2014-02-04T11:00:00 & 0.36 \\
\hline & 2014-02-04T12:00:00 & 0.33 \\
\hline & 2014-02-04T13:00:00 & 0.31 \\
\hline \multirow[t]{5}{*}{ No.3 } & $2014-03-14 \mathrm{~T} 10: 00: 00$ & 0.41 \\
\hline & $2014-03-14 T 11: 00: 00$ & 0.42 \\
\hline & $2014-03-14 T 12: 00: 00$ & 0.33 \\
\hline & $2014-03-14 T 8: 00: 00$ & 0.36 \\
\hline & 2014-03-14T9:00:00 & 0.37 \\
\hline \multirow[t]{2}{*}{ No.4 } & 2014-03-27T13:00:00 & 0.31 \\
\hline & 2014-03-27Т14:00:00 & 0.34 \\
\hline \multirow[t]{4}{*}{ No.5 } & 2014-05-06T10:00:00 & 0.44 \\
\hline & 2014-05-06T11:00:00 & 0.42 \\
\hline & 2014-05-06T12:00:00 & 0.40 \\
\hline & 2014-05-06T9:00:00 & 0.37 \\
\hline
\end{tabular}

\begin{tabular}{|c|c|c|}
\hline & yyyy-mm-dd hour & normalized errors \\
\hline \multirow[t]{4}{*}{ No.6 } & 2014-07-08T13:00:00 & -0.31 \\
\hline & 2014-07-08T15:00:00 & -0.34 \\
\hline & 2014-07-08T16:00:00 & -0.37 \\
\hline & 2014-07-08T17:00:00 & -0.33 \\
\hline No.7 & 2014-07-23T9:00:00 & -0.35 \\
\hline \multirow[t]{3}{*}{ No.8 } & 2014-08-04T17:00:00 & -0.32 \\
\hline & 2014-08-04T7:00:00 & -0.30 \\
\hline & 2014-08-04T9:00:00 & -0.30 \\
\hline No.9 & 2014-08-08T8:00:00 & -0.31 \\
\hline \multirow[t]{4}{*}{ No.10 } & 2014-08-24T10:00:00 & -0.39 \\
\hline & 2014-08-24T11:00:00 & -0.31 \\
\hline & 2014-08-24T8:00:00 & -0.32 \\
\hline & 2014-08-24T9:00:00 & -0.31 \\
\hline No.11 & $2014-10-27 T 10: 00: 00$ & -0.37 \\
\hline \multirow[t]{2}{*}{ No.12 } & $2014-12-10 T 13: 00: 00$ & 0.30 \\
\hline & 2014-12-10T14:00:00 & 0.31 \\
\hline No.13 & $2014-12-12 \mathrm{~T} 13: 00: 00$ & 0.30 \\
\hline
\end{tabular}


(a)

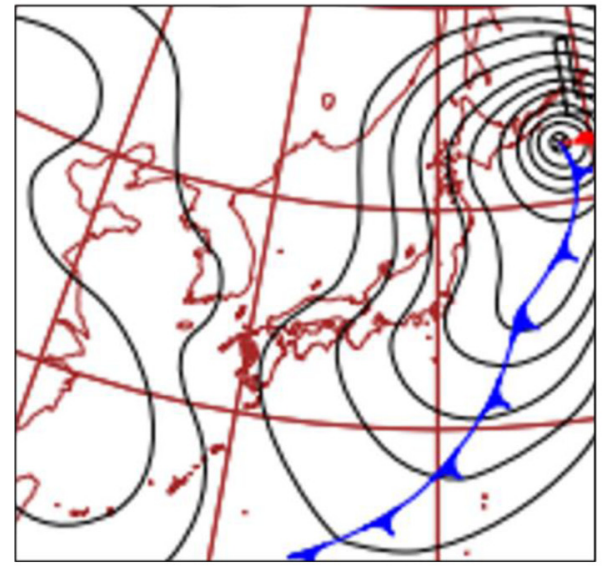

(b)

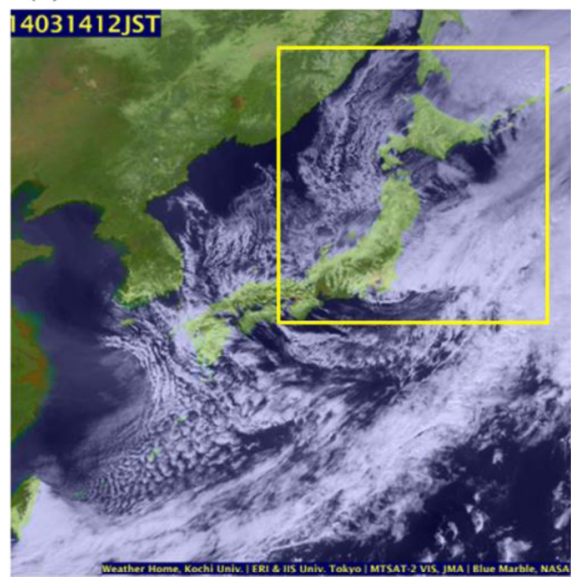

Fig. 2. (a) Surface weather chart around eastern Asia on 09 Japan standard time (JST) on March 14, 2014. (b) Satellite visible image at 12 JST on the same day.

(a) MSM

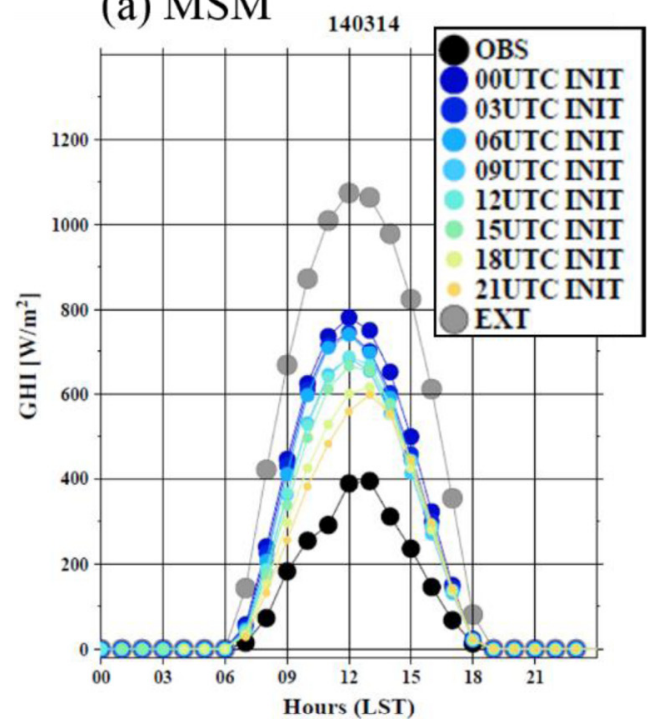

(b) LFM

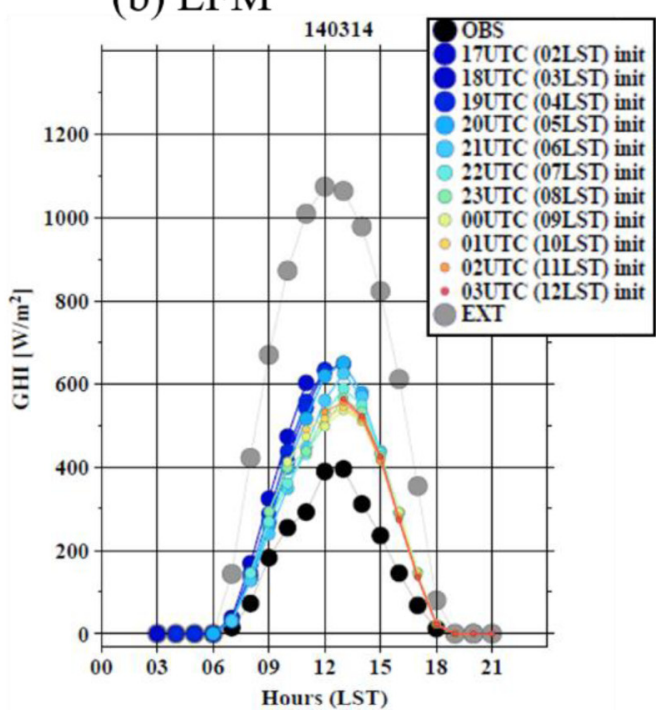

Fig. 3. Time series of hourly GHI values on March 14, 2014 for TEPCO area. (a) MSM and (b) LFM forecasts. Observations (black circles), extra solar irradiance (gray circles), forecasts with different initialization times (colors) are shown.

observations. LFM GHI forecasts tend to be close the observations compared with the MSM day ahead forecasts (Fig. 3b). However, the overestimation due to the underestimation of cloud fields is remained, even in the finer resolution model.

\subsection{Cloud fields from MSM and LFM}

Whether cloud fields can be represented or not is the most important point for GHI forecasts at the surface for regional area. We also compared cloud fields between satellite visible image and MSM forecasts from difference initialization times. Figure $4 \mathrm{a}$ shows a close-up view of the square region of Figure $2 \mathrm{~b}$. Figure $4 \mathrm{~b}$ shows forecasted cloud field distribution with 03 UTC initialization time (corresponds to 12 JST on a previous day), which means $24 \mathrm{~h}$ ahead forecasts. Compared with the satellite visible image (Fig. 4a), cloud fields cannot be reproduced in MSM around the TEPCO area and on the eastern part of TEPCO region (or the western part of the Pacific Ocean). However, MSM cloud field forecasts with 21 UTC initialization time (06 JST on a target day) can be close to the observed cloud fields on the eastern part of TEPCO region. Relatively wider cloud regions are found even over the TEPCO region compared with MSM forecasts with 03 UTC initialization time. The shorter lead time of forecasts, a representation of cloud regions tend to be also improved. Noted that time series of GHI forecast shown in Figure 3 again, MSM GHI forecasts with 21 UTC initialization time for the TEPCO area become close to GHI observations. In a most recent forecast, new meteorological observations data sets are included in the initialization process in MSM forecasts through data assimilation. Therefore, forecast errors of cloud fields (or GHI values) tend to be decreased. 
(a)12JST@VIS

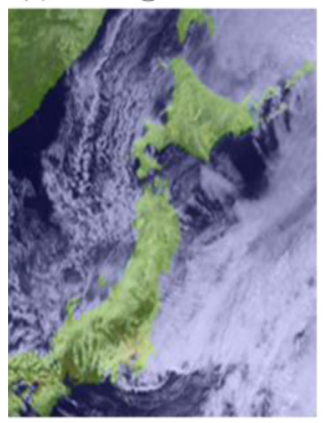

(b) 12JST on a previous day

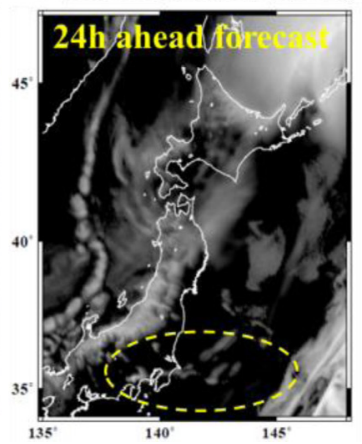

(c) 6JST on a target day

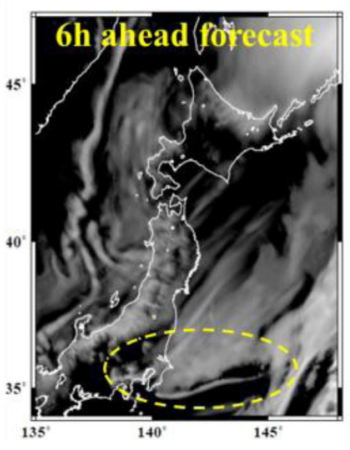

(d) 6JST on a target day

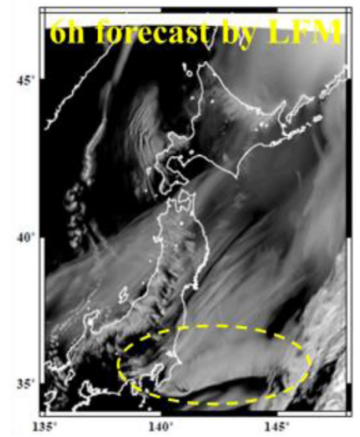

Fig. 4. Comparison of cloud fields at 12 JST on March 14, 2014. (a) Satellite visible image (close-up view of the yellow square shown in Fig. 2b), (b) $24 \mathrm{~h}$ forecasts from the MSM, (c) $6 \mathrm{~h}$ forecasts from MSM and (d) $6 \mathrm{~h}$ forecast from the LFM.

Figure 4d shows cloud fields forecasts from LFM of $2 \mathrm{~km}$ horizontal grid spacing with 21 UTC initialization time $(6 \mathrm{~h}$ ahead forecast). Compared to the MSM (Fig. 4c), cloud fields forecasted from the finer model LFM were similar to those of MSM. However, cloud fields from even the LFM tend to have large forecast errors compared to satellite observations, because uncertainties of both model schemes and meteorological observations (observation errors, observation density, etc.) are remained.

\section{Summary}

In this study, a case study of large GHI forecast errors (i.e., outlier events) on March 14, 2014 from the two NWPs (or MSM and LFM) were investigated for the regional area where is controlled by the Tokyo electric power company, TEPCO. From validation results, it seems that the location of forecasted cloud fields with a low pressure cold front over the western part of the Pacific Ocean in one-day ahead forecast by the MSM is different from that by satellite observations. However, we confirmed that target day's forecasts with early morning initialization time (relatively short lead time forecasts) can reproduce the location of cloud fields which is similar to satellite observations, because the latest observational datasets tend to be assimilated to the model.

Basically development of physical and/or radiation processes of NWPs will be necessary. In addition, heralding large GHI forecast errors for a regional area (such as the TEPCO area) at the daytime of a previous day would be also expected for the field of the EMS in a future study.

Satellite visible images were used from the web site of Kochi University (http://weather.is.kochi-u.ac.jp/) [7]. This study was carried out in collaboration with the Meteorological Research Institute (MRI) of the JMA. This study is supported by a CREST project of the Japan Science and Technology Agency (JST).

\section{References}

1. H. Ohtake, J.G. da Silva Fonseca Jr., T. Takashima, T. Oozeki, K. Shimose, Y. Yamada, Sol. Energy 116, 83 (2015), DOI:10.1016/j.solener.2015.03.020

2. H. Ohtake, J.G. da Silva Fonseca Jr., T. Takashima, T. Oozeki, K. Shimose, Y. Yamada, Sol. Energy 98, 128 (2013), DOI:10.1016/j.solener.2012.10.007

3. H. Ohtake, J.G. da Silva Fonseca Jr., T. Takashima, T. Oozeki, Y. Yamada, Energy Proc. 59, 278 (2014), DOI:10.1016/j.egypro.2014.10.378

4. The web site of the JST, CREST/EMS TEEDDA Team: http://helios.aori.u-tokyo.ac.jp/teedda/fs/about.html

5. The JMA web site. Outline NWP March 2013: http://www. jma.go.jp/jma/jma-eng/jma-center/nwp/outline2013-nwp/ index.htm

6. K. Saito, T. Fujita, Y. Yamada, J. Ishida, Y. Kumagai et al., Mon. Weather Rev. 134, 1266 (2006), DOI:10.1175/MWR3120.1

7. The web site of Kochi University: http://weather.is.kochi-u.ac.jp

Cite this article as: Hideaki Ohtake, Takumi Takashima, Takashi Oozeki, Joao Gari da Silva Fonseca Jr., Yoshinori Yamada, A case study of outlier event on solar irradiance forecasts from the two NWPs with different horizontal resolutions, Renew. Energy Environ. Sustain. 1, $37(2016)$ 